\title{
Effect of the lonic Concentration of Simulated Body Fluid on the Minerals Formed on Crosslinked Elastin-Like Polypeptide Membranes
}

Ophélie Gourgas ${ }^{1}$, Gregory B. Cole ${ }^{2,3}$, Lisa D. Muiznieks ${ }^{2}$, Simon Sharpe ${ }^{2,3}$, Marta Cerruti ${ }^{1 *}$.

${ }^{1}$ Department of Mining and Materials Engineering, McGill University, Montreal, Canada;

${ }^{2}$ Molecular Medicine, Hospital for Sick Children, Toronto, ON, Canada;

${ }^{3}$ Department of Biochemistry, University of Toronto, Toronto, ON, Canada;

* Corresponding author at: Materials Engineering, McGill University, 3610 University St., 2M020 Wong Building, Montreal, Quebec H3A 0C5, Canada. E-mail address: marta.cerruti@mcgill.ca (M. Cerruti). Phone number: 5143985496.

\section{SUPPLEMENTAL MATERIAL}

This document contains supplemental material related to:

- Section 1: Detailed methods

- Section 2: Supplemental figures and tables

- Section 3: Supplemental references 


\section{Section 1: Detailed methods}

\section{Determination of the apatite ionic activity products (IP) and degree of supersaturation (S)}

An increase in concentration of calcium $(\mathrm{Ca})$ and phosphate $(\mathrm{P})$ ions in the simulated body fluid (SBF) leads to an increase in the apatite ionic activity product (IP) of the SBF.

Formation of hydroxyapatite (HA) from its constituent ions is given by the following equilibrium (1):

$$
\mathrm{Ca}_{10}\left(\mathrm{PO}_{4}\right)_{6}(\mathrm{OH})_{2} \Leftrightarrow 10 \mathrm{Ca}^{2+}+6 \mathrm{PO}_{4}{ }^{3-}+2 \mathrm{OH}^{-},(\mathrm{i})
$$

The ionic activity product (IP) of HA in an aqueous solution is this given by the following equation (1):

$$
\mathrm{IP}=\left(\gamma \mathrm{Ca}^{2+}\right)^{10}\left(\gamma \mathrm{PO}^{3-}\right)^{10}\left(\gamma \mathrm{OH}^{-}\right)^{2}\left[\mathrm{Ca}^{2+}\right]^{10}\left[\mathrm{PO}_{4}^{3-}\right]^{6}\left[\mathrm{OH}^{-}\right]^{2},(\mathrm{ii})
$$

where $\gamma$ is the activity coefficient, and [ ] represents ionic concentration.

The activity coefficients were calculated based on the modified Debye-Hückel equation proposed by Davies (2). The IP of each SBF solution is given in Table S1.

The relative degree of supersaturation $S$ with respect to apatite phases was calculating using the following equation (1):

$$
S=\left(I P / K_{s p}\right)^{1 / n},(\text { iii })
$$

where IP is the ionic activity, $\mathrm{K}_{\mathrm{sp}}$ the solubility product, and $\mathrm{n}$ the number of ions in a formula unit (i.e. 18 for apatite). $\mathrm{K}_{\mathrm{sp}}$ of apatite in water is $5.5 \times 10^{-118}$ at $37^{\circ} \mathrm{C}(3)$.

The degree of supersaturation S of each SBF solution in respect to apatite is given in Table S1. 


\section{Determination of the crystallinity index $(\mathrm{Cl})$ of the minerals by FTIR}

The splitting of the $\mathrm{v}_{4} \mathrm{PO}_{4}{ }^{3-}$ band can be used to estimate $\mathrm{HA}$ crystallinity index $(\mathrm{Cl})$ according to the formula introduced by Shemesh et al. (4):

$$
\mathrm{Cl}=(\mathrm{A} 602+\mathrm{A} 562) / \mathrm{A} 588,(\mathrm{iv})
$$

where $A x$ is the absorbance at wavenumber $x$ (Figure S7)

A higher degree of splitting and therefore a higher $\mathrm{Cl}$ correspond to more crystalline materials (5).

\section{Ca K-edge Near Edge X-ray absorption fine structure (Ca K-edge NEXAFS) spectroscopy}

- Spectra acquisition

We used NEXAFS spectroscopy to identify and quantify the Ca-P phases present in the samples. NEXAFS is a synchrotron-based technique that allows analyzing how $\mathrm{x}$-rays are absorbed by an atom at energies near the core-level binding energies of that atom depending on its chemical and physical environment (6). Because of crystallinity is not required for NEXAFS measurements, this technique is well suited for analysis of non-crystalline or poorly crystalline phases (6). Also, NEXAFS is more sensitive than traditional spectroscopic techniques, with a detection limit that can be as low as few ppm. Thus, NEXAFS is an excellent tool to analyze et differentiate the Ca-P phases present in calcified ELP 3 membranes.

Ca K-edge spectra were collected in fluorescence mode with energies between 1.7 and 10 $\mathrm{keV}$ and with a photon beam spot size of $2 \mathrm{~mm} \times 6 \mathrm{~mm}$. The storage ring energy during data collection was $2.9 \mathrm{GeV}$ ant the current around $200 \mathrm{~mA}$. The X-ray beam was monochromated by $\mathrm{Si}(111)$ crystals with energy resolution $(\Delta \mathrm{E} / \mathrm{E})$ of $10^{-4}$. 


\section{- Data analysis}

We first selected seven reference compounds (Figure S6). The first one is $\mathrm{ELP}_{3}$ membranes incubated in $3.8 \mathrm{mM} \mathrm{CaCl}_{2}$ for 16 days $\left(\mathrm{ELP}_{3}-\mathrm{Ca}^{2+}\right)$. This serves as a model of $\mathrm{Ca}$ ions adsorbed on ELP 3 . The other five references are Ca species that are known to be present in pathological calcifications: amorphous calcium phosphate (ACP), octacalcium phosphate (OCP), dicalcium phosphate dihydrate (DCPD), hydroxyapatite (HA), carbonated hydroxyapatite $(\mathrm{CHA})$, and $\beta$ tricalcium phosphate ( $\beta$-TCMP) (7-13).

To determine and quantify the Ca-P phases in the $\mathrm{ELP}_{3}$ samples, we performed linear combination fitting (LCF) analysis using Athena software (Demeter 0.9.20). LCF is justified because the x-ray absorption from different species in a sample is additive (14). The total absorption coefficient calculated by LCF can be written as:

$$
M=\Sigma_{i} f_{i}\left(S T D_{i}\right),(v)
$$

where $M$ is the least square fit to the sample spectrum, $\left(S T D_{i}\right)$ represents the absorption coefficient of the standard reference spectra, and $f_{i}$ is the fraction of each reference spectrum in the sample spectrum, summed over the number of references, i. Thus, with appropriate standard references, LCF can identify and quantify the fraction of chemical species in an unknown sample (14).

We first performed principal component analysis (PCA) to determine which reference compounds should be excluded for the LCF fitting and thus avoid using an excessive number of standard compounds. PCA results showed that DCPD and $\beta$-TCMP were not likely present in the calcified membranes. Thus, we used $\mathrm{ELP}_{3}-\mathrm{Ca}^{2+}, \mathrm{ACP}, \mathrm{OCP}, \mathrm{HA}$, and $\mathrm{CHA}$ as references for the LCF analysis. We performed LCF using all the possible combinations of the selected reference compounds. We evaluated the quality of the fits using the R-factor: fitting results with R-factor values below 0.02 are considered satisfactory (15). We reported the LCF combination giving the lowest $R$-factor for each sample analyzed (Table S16). 


\section{Section 2: Supplemental figures and tables}

Amino acid sequence

Domain schematic
AAAAAKAAKYGA

$(\text { GVPGV })_{7}$

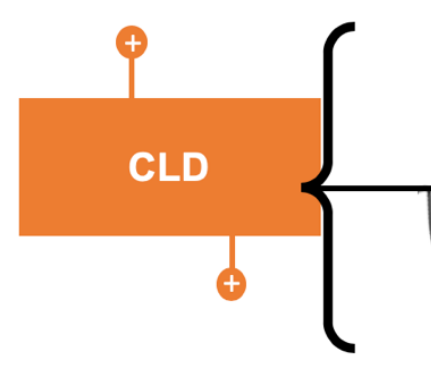

AAAAAKAAKYGA

HP

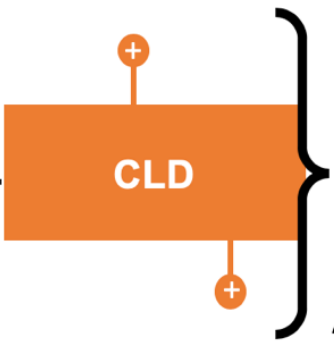

Figure S1. The repeating amino acid sequence and alternating domain architecture of ELP 3. Crosslinking domains (CLD) and hydrophobic domains (HP) are represented as orange rectangles and springs, respectively.

Table S1. Ion concentrations, apatite ionic activity products (IP), and degree of supersaturation (S) of human blood plasma, 1 x, 1.5 x, 2 x, and $3 \times$ simulated body fluid (SBF) solutions.

Ion concentration $(\mathrm{mM})$

\begin{tabular}{ccccccccccc} 
Solution & $\mathrm{Na}^{+}$ & $\mathrm{K}^{+}$ & $\mathrm{Mg}^{2+}$ & $\mathrm{Ca}^{2+}$ & $\mathrm{Cl}^{-}$ & $\mathrm{HCO}_{3}{ }^{-}$ & $\mathrm{HPO}_{4}^{2-}$ & $\mathrm{SO}_{4}^{2-}$ & $\mathrm{Log} \mathrm{IP}$ & $\mathrm{S}$ \\
\hline $\begin{array}{c}\text { Blood } \\
\text { plasma }\end{array}$ & 142.0 & 5.0 & 1.5 & 2.5 & 103.0 & 27.0 & 1.0 & 0.5 & -96.6 & 14 \\
$1 \times$ xBF & 142.0 & 5.0 & 1.5 & 2.5 & 147.8 & 4.2 & 1.0 & 0.5 & -96.6 & 14 \\
$1.5 \times \mathrm{SBF}$ & 211.5 & 7.5 & 2.4 & 3.8 & 228.0 & 6.3 & 1.5 & 0.8 & -93.8 & 20 \\
$2 \times \mathrm{SBF}$ & 282.0 & 10.0 & 3.0 & 5.0 & 304.0 & 8.4 & 2.0 & 1.0 & -91.9 & 26 \\
$3 \times \mathrm{SBF}$ & 423.0 & 15.0 & 4.8 & 7.6 & 456.0 & 12.6 & 3.0 & 1.6 & -87.5 & 45 \\
\hline
\end{tabular}



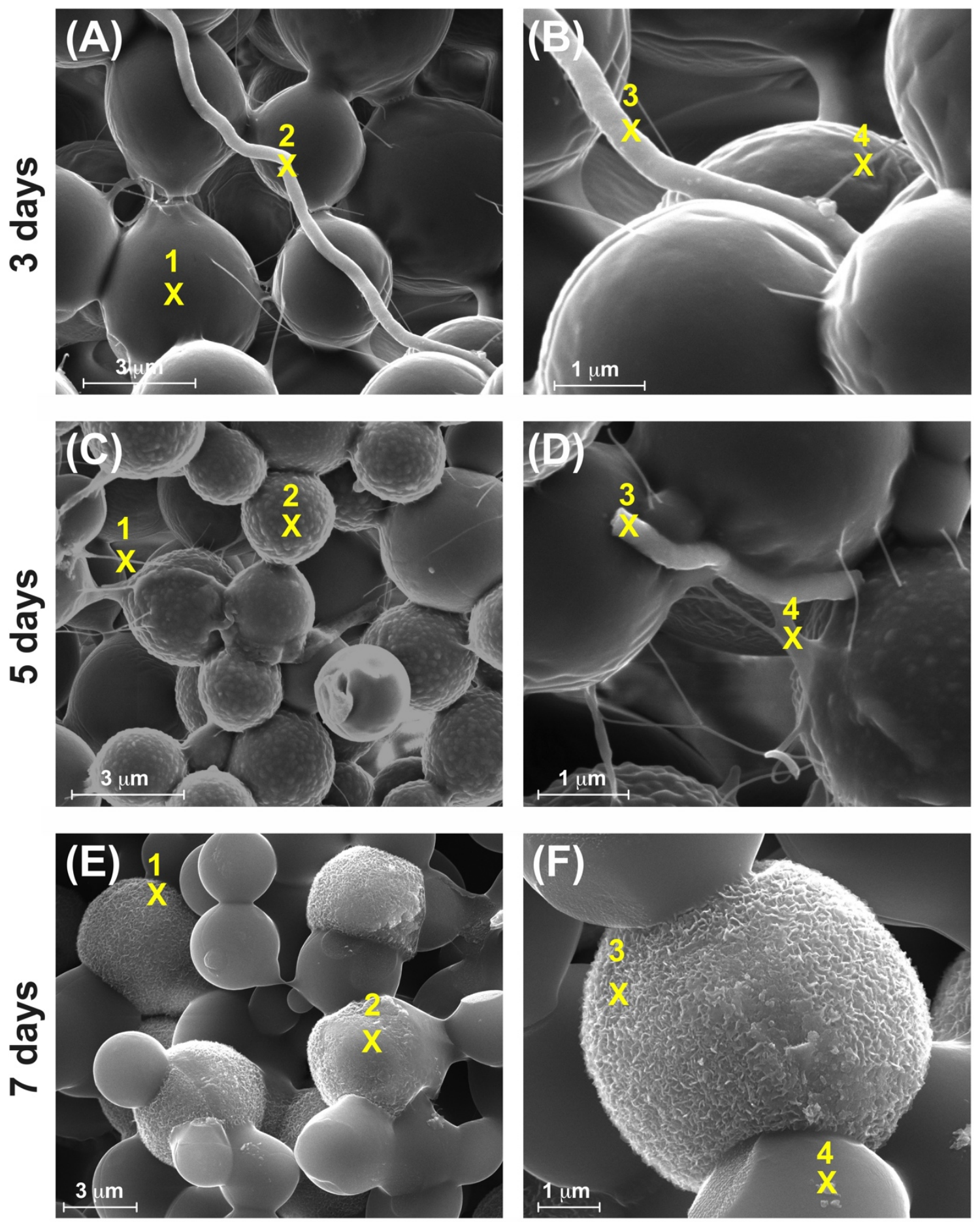

Figure S2. SEM images of ELP 3 membranes after incubation in $1.5 \times \mathrm{SBF}$ for $(\mathbf{A}$ and $\mathbf{B}) 3,(\mathbf{C}$ and D) 5 , and ( $E$ and $F) 7$ days. The spots marked with " $X$ " on all panels indicate the spots where EDS spectra were collected and they correspond to the data presented in Tables S2 (spots in A, B), S4 (spots in C, D), and S5 (spots in E, F). 
Table S2. Relative elemental atomic percentages measured by EDS in $\mathrm{ELP}_{3}$ membranes incubated in $1.5 \times$ SBF for 3 days. The spots 1-4 are shown in Figures S2A and S2B.

\begin{tabular}{cccccccccc}
\hline Spot & $\mathrm{C}(\mathrm{at} \%)$ & $\mathrm{O}(\mathrm{at} \%)$ & $\mathrm{N}(\mathrm{at} \%)$ & $\mathrm{Ca}(\mathrm{at} \%)$ & $\mathrm{P}(\mathrm{at} \%)$ & $\mathrm{O} / \mathrm{C}$ & $\mathrm{N} / \mathrm{C}$ & $\mathrm{Ca} / \mathrm{P}$ & $\mathrm{N} / \mathrm{Ca}$ \\
\hline 1 & 67.2 & 17.8 & 15.0 & 0 & 0 & 0.26 & 0.22 & $/$ & $/$ \\
2 & 64.8 & 21.6 & 12.9 & 0.4 & 0.3 & 0.33 & 0.20 & 1.3 & 32.3 \\
3 & 64.4 & 26.3 & 7.4 & 1.3 & 0.9 & 0.41 & 0.11 & 1.4 & 5.7 \\
4 & 68.1 & 20.8 & 10.4 & 0.6 & 0.1 & 0.31 & 0.15 & 6.0 & 17.3 \\
\hline
\end{tabular}

Table S3. List of Ca-P compounds found in pathological calcifications and their $\mathrm{Ca} / \mathrm{P}$ atomic ratios (16).

\begin{tabular}{|c|c|c|}
\hline Name & Formula & $\mathrm{Ca} / \mathrm{P}$ ratio \\
\hline Amorphous calcium phosphate (ACP) & $\mathrm{Ca}_{3}\left(\mathrm{PO}_{4}\right)_{2 .} \cdot 3 \mathrm{H}_{2} \mathrm{O}$ & 1.5 \\
\hline Octacalcium phosphate (OCP) & $\mathrm{Ca}_{8} \mathrm{H}_{2}\left(\mathrm{PO}_{4}\right)_{6} .5 \mathrm{H}_{2} \mathrm{O}$ & 1.33 \\
\hline Dicalcium phosphate dihydrate (DCPD) & $\mathrm{Ca}\left(\mathrm{HPO}_{4}\right) \cdot 2 \mathrm{H}_{2} \mathrm{O}$ & 1.0 \\
\hline $\begin{array}{c}\text { Magnesium- substituted } \beta \text {-tricalcium } \\
\text { phosphate }(\beta \text {-TCMP) }\end{array}$ & $\mathrm{Ca}_{18}(\mathrm{Mg})_{2} \mathrm{H}_{2}\left(\mathrm{PO}_{4}\right)_{14}$ & 1.29 \\
\hline Hydroxyapatite (HA) & $\mathrm{Ca}_{10}\left(\mathrm{PO}_{4}\right)_{6}(\mathrm{OH})_{2}$ & 1.67 \\
\hline Carbonated hydroxyapatite $(\mathrm{CHA})$ & $\mathrm{Ca}_{10-\mathrm{p}}\left(\mathrm{PO}_{4}\right)_{6-\mathrm{p}}(\mathrm{OH})_{2-\mathrm{p}}\left(\mathrm{CO}_{3}\right)_{\mathrm{p}}(0<\mathrm{p}<1)$ & $>1.67$ \\
\hline Calcium-deficient HA & $\mathrm{Ca}_{10-x}\left(\mathrm{HPO}_{4}\right)_{x}\left(\mathrm{PO}_{4}\right)_{6-x}(\mathrm{OH})_{2-x}(0<x<1)$ & $1.3-1.67$ \\
\hline
\end{tabular}

Stoichiometric apatite is given by the chemical formula $\mathrm{Ca}_{10}\left(\mathrm{PO}_{4}\right)_{6}(\mathrm{OH})_{2}$, with a $\mathrm{Ca} / \mathrm{P}$ atomic ratio of 1.67 (16). When apatite forms, both in vivo and in vitro, some sites for the $\mathrm{PO}_{4}{ }^{3-}$ ion can be partially substituted by $\mathrm{CO}_{3}{ }^{2-}$ and $\mathrm{HPO}_{4}{ }^{2-}$ ions. One substitution of $\mathrm{CO}_{3}{ }^{2-}$ for $\mathrm{PO}_{4}{ }^{3-}$ results in a half $\mathrm{Ca}$ and one $\mathrm{P}$ deficiencies, thus giving a $\mathrm{Ca} / \mathrm{P}$ ratio higher than 1.67. On the contrary, one substitution of $\mathrm{HPO}_{4}{ }^{2-}$ for $\mathrm{PO}_{4}{ }^{3-}$ results only in a half $\mathrm{Ca}$ deficiency, to give a $\mathrm{Ca} / \mathrm{P}$ ratio lower than $1.67(16)$. 
Table S4. Relative elemental atomic percentages measured by EDS in $\mathrm{ELP}_{3}$ membranes incubated in $1.5 \times$ SBF for 5 days. The spots 1-4 are shown in Figures S2C and S2D.

\begin{tabular}{cccccccccc}
\hline Spot & $\mathrm{C}(\mathrm{at} \%)$ & $\mathrm{O}(\mathrm{at} \%)$ & $\mathrm{N}(\mathrm{at} \%)$ & $\mathrm{Ca}(\mathrm{at} \%)$ & $\mathrm{P}($ at $\%)$ & $\mathrm{O} / \mathrm{C}$ & $\mathrm{N} / \mathrm{C}$ & $\mathrm{Ca} / \mathrm{P}$ & $\mathrm{N} / \mathrm{Ca}$ \\
\hline 1 & 60.4 & 21.3 & 15.7 & 1.5 & 1.1 & 0.35 & 0.26 & 1.4 & 10.5 \\
2 & 65.1 & 21.8 & 12.4 & 0.6 & 0.1 & 0.33 & 0.19 & 6 & 20.7 \\
3 & 52.8 & 25.4 & 17.7 & 2.5 & 1.6 & 0.48 & 0.34 & 1.6 & 7.1 \\
4 & 61.2 & 20.9 & 16.7 & 1.0 & 0.2 & 0.34 & 0.27 & 5 & 16.7 \\
\hline
\end{tabular}

Table S5. Relative elemental atomic percentages measured by EDS in $\mathrm{ELP}_{3}$ membranes incubated in $1.5 \times$ SBF for 7 days. The spots 1-4 are shown in Figures S2E and S2F.

\begin{tabular}{cccccccccc}
\hline Spot & $\mathrm{C}(\mathrm{at} \%)$ & $\mathrm{O}(\mathrm{at} \%)$ & $\mathrm{N}(\mathrm{at} \%)$ & $\mathrm{Ca}(\mathrm{at} \%)$ & $\mathrm{P}($ at $\%)$ & $\mathrm{O} / \mathrm{C}$ & $\mathrm{N} / \mathrm{C}$ & $\mathrm{Ca} / \mathrm{P}$ & $\mathrm{N} / \mathrm{Ca}$ \\
\hline 1 & 30.3 & 46.0 & 6.1 & 10.9 & 6.6 & 1.52 & 0.20 & 1.7 & 0.56 \\
2 & 33.0 & 48.6 & 3.6 & 9.0 & 5.8 & 1.47 & 0.05 & 1.6 & 0.40 \\
3 & 40.4 & 40.0 & 3.9 & 9.6 & 6.1 & 0.99 & 0.10 & 1.6 & 0.41 \\
4 & 67.4 & 17.4 & 13.6 & 1.4 & 0.3 & 0.26 & 0.20 & 4.7 & 9.7 \\
\hline
\end{tabular}



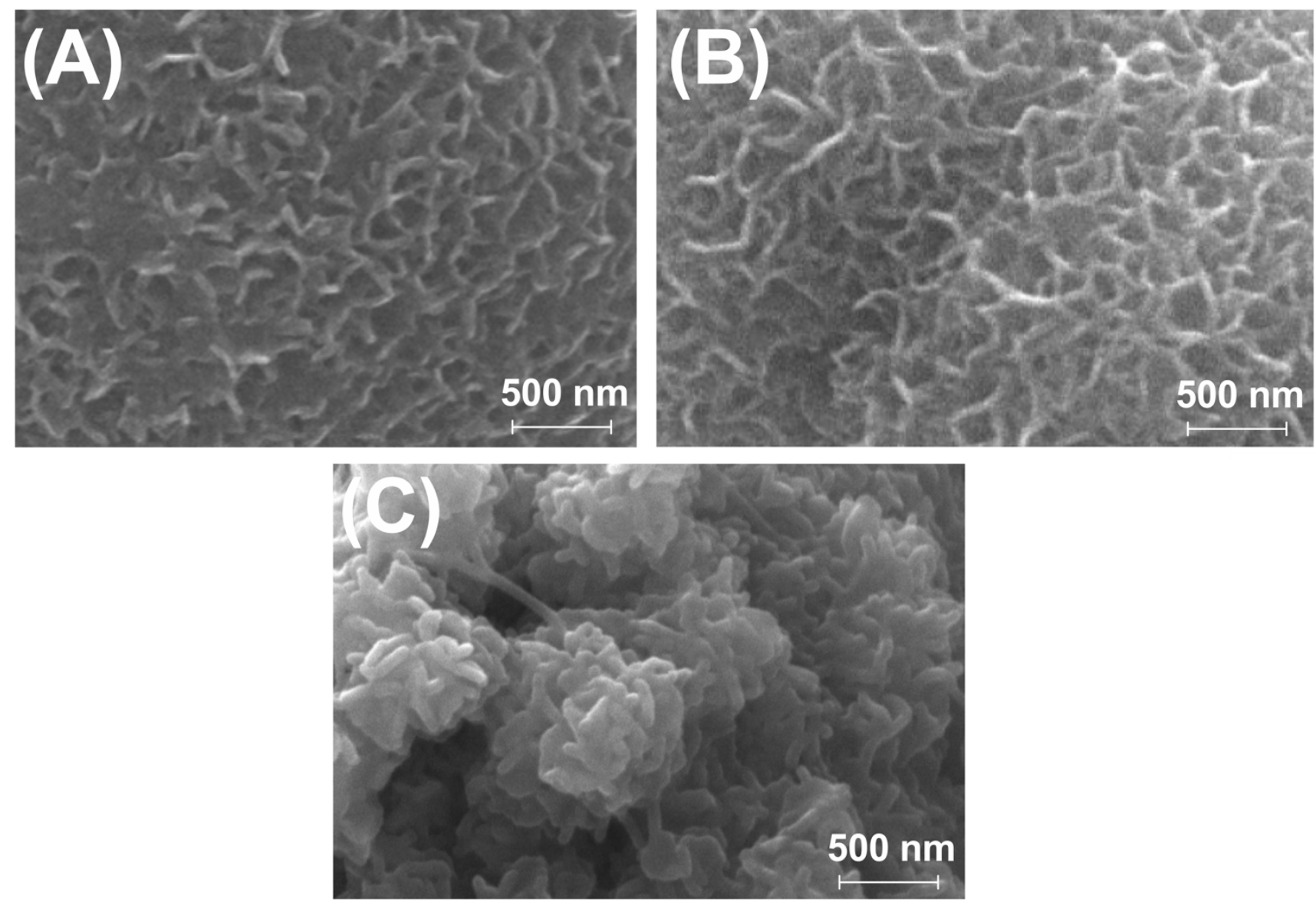

Figure S3. (A - C) Highly magnified nanoscale structures of the minerals after 7 days in (A) $1.5 \mathrm{x},(\mathrm{B}) 2 \mathrm{x},(\mathrm{C}), 3 \mathrm{x}$ SBF solutions. 

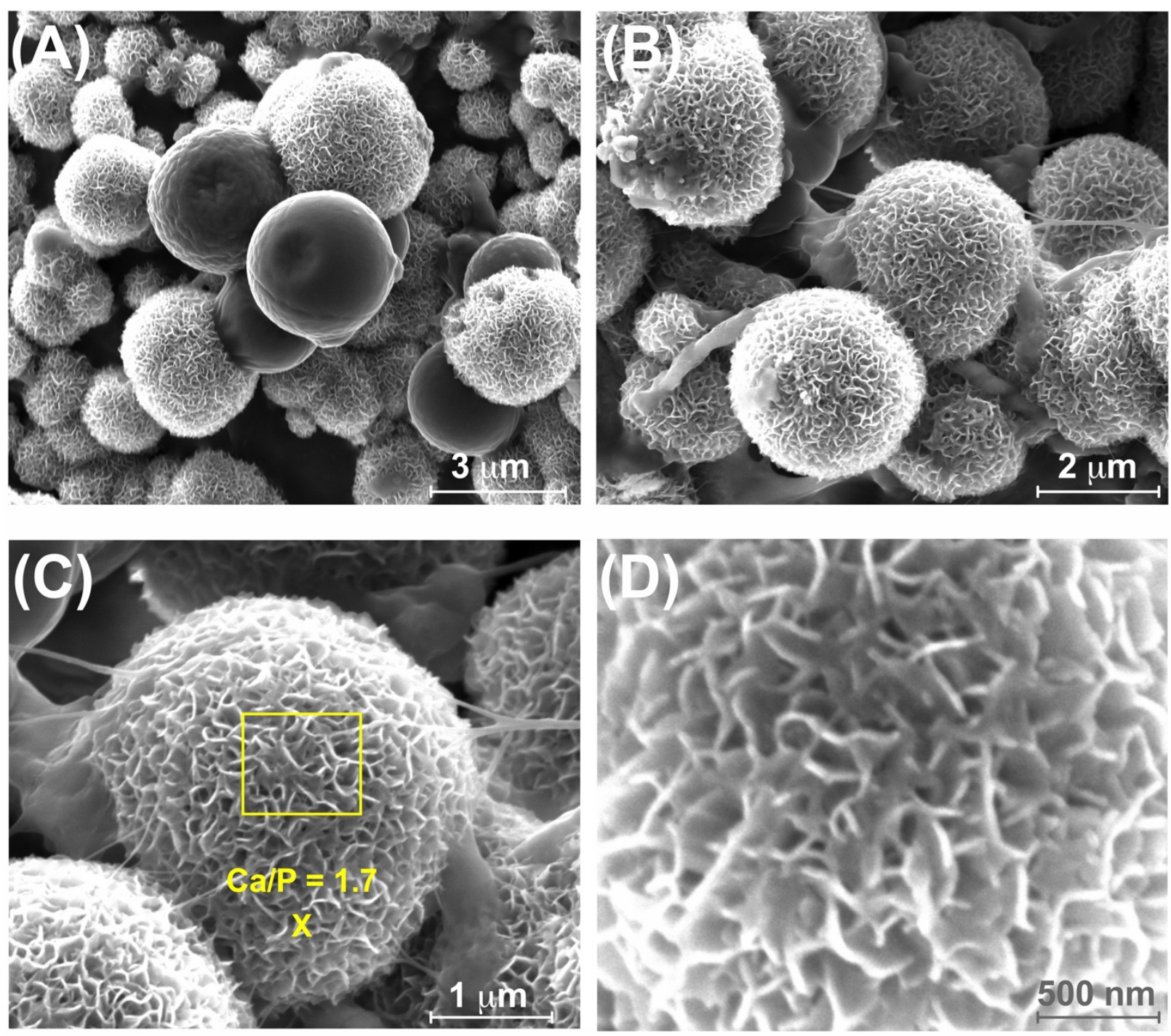

Figure S4. SEM images of $\mathrm{ELP}_{3}$ membranes after incubation in $1.5 \times \mathrm{SBF}$ for 21 days. The $\mathrm{Ca} / \mathrm{P}$ ratio indicated on $\mathbf{C}$ is based on elemental atomic percentages obtained by ED and (D) is the magnification of the highlighted region in (C). 

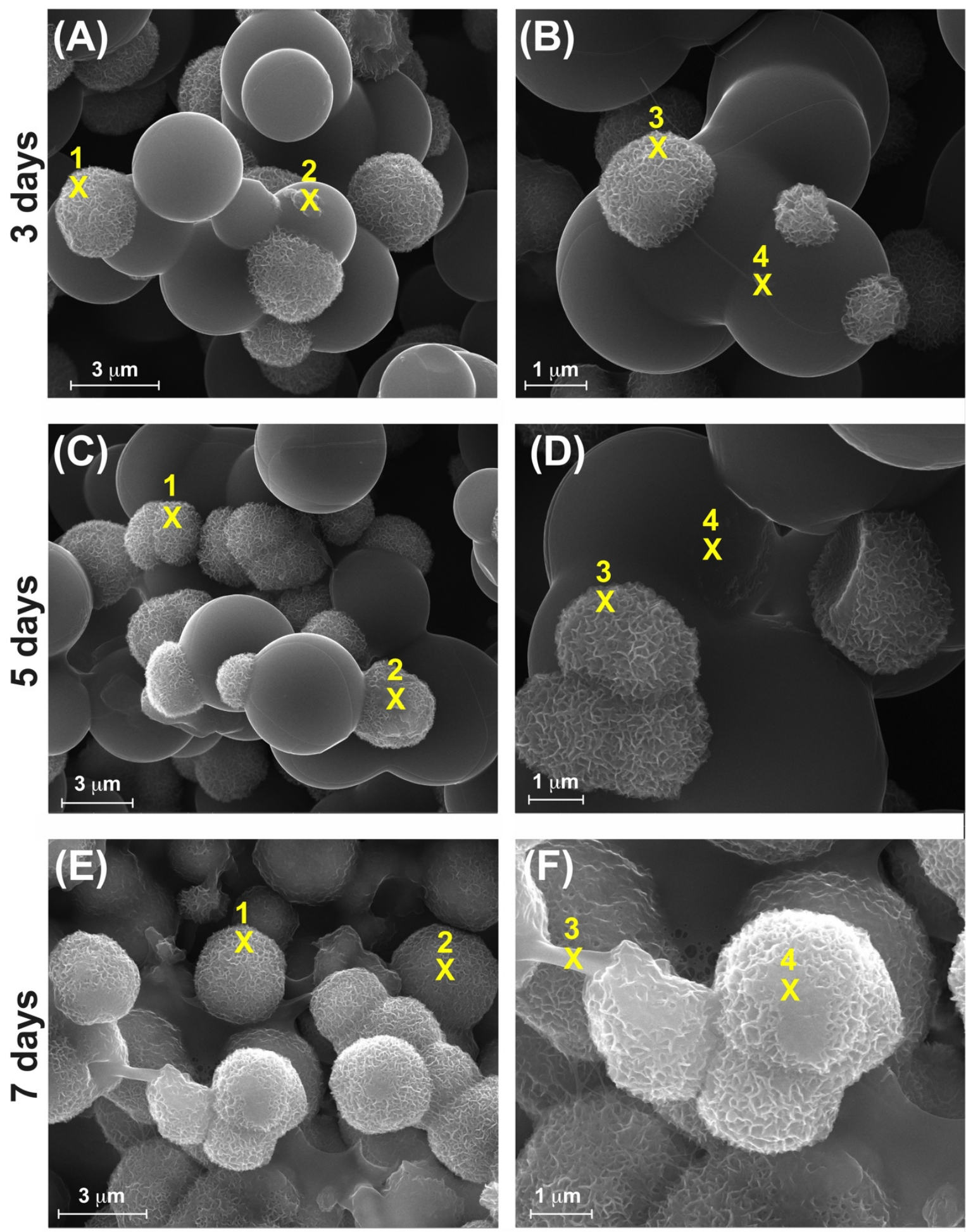

Figure S5. SEM images of ELP 3 membranes after incubation in $2 \times \mathrm{SBF}$ for (A and $\mathbf{B}) 3$, (C and $\mathbf{D}) 5$, and (E and F) 7 days. The spots marked with "X" on all panels indicate the spots where EDS spectra were collected and they correspond to the data presented in Tables S6 (spots in A, B), S7 (spots in C, D), and S8 (spots in E, F). 
Table S6. Relative elemental atomic percentages measured by EDS in $\mathrm{ELP}_{3}$ membranes incubated in $2 \times$ SBF for 3 days. The spots 1-4 are shown in Figures S5A and S5B.

\begin{tabular}{cccccccccc}
\hline Spot & $\mathrm{C}(\mathrm{at} \%)$ & $\mathrm{O}($ at $\%)$ & $\mathrm{N}(\mathrm{at} \%)$ & $\mathrm{Ca}(\mathrm{at} \%)$ & $\mathrm{P}($ at $\%)$ & $\mathrm{O} / \mathrm{C}$ & $\mathrm{N} / \mathrm{C}$ & $\mathrm{Ca} / \mathrm{P}$ & $\mathrm{N} / \mathrm{Ca}$ \\
\hline 1 & 36.0 & 44.6 & 3.2 & 9.7 & 6.5 & 1.24 & 0.09 & 1.5 & 0.33 \\
2 & 61.8 & 17.7 & 18.7 & 1.7 & 0.2 & 0.29 & 0.30 & 8.5 & 11.0 \\
3 & 67.5 & 19.3 & 6.2 & 4.1 & 2.9 & 0.29 & 0.09 & 1.4 & 1.5 \\
4 & 59.9 & 22.1 & 17.0 & 0.9 & 0.1 & 0.37 & 0.28 & 9.0 & 18.9 \\
\hline
\end{tabular}

Table S7. Relative elemental atomic percentages measured by EDS in $\mathrm{ELP}_{3}$ membranes incubated in 2 x SBF for 5 days. The spots 1-4 are shown in Figures S5C and S5D.

\begin{tabular}{cccccccccc}
\hline Spot & $\mathrm{C}($ at\%) & $\mathrm{O}(\mathrm{at} \%)$ & $\mathrm{N}(\mathrm{at} \%)$ & $\mathrm{Ca}($ at\%) & $\mathrm{P}(\mathrm{at} \%)$ & $\mathrm{O} / \mathrm{C}$ & $\mathrm{N} / \mathrm{C}$ & $\mathrm{Ca} / \mathrm{P}$ & $\mathrm{N} / \mathrm{Ca}$ \\
\hline 1 & 45.8 & 38.1 & 1.9 & 7.1 & 4.8 & 0.83 & 0.04 & 1.5 & 0.27 \\
2 & 52.4 & 30.2 & 11.7 & 3.4 & 2.3 & 0.58 & 0.22 & 1.5 & 3.44 \\
3 & 27.5 & 51.5 & 5.0 & 9.3 & 6.6 & 1.87 & 0.18 & 1.4 & 0.54 \\
4 & 60.0 & 23.2 & 15.8 & 0.8 & 0.2 & 0.39 & 0.26 & 4.0 & 19.8 \\
\hline
\end{tabular}

Table S8. Relative elemental atomic percentages measured by EDS in $\mathrm{ELP}_{3}$ membranes incubated in $2 \times$ SBF for 7 days. The spots 1-4 are shown in Figures S5E and S5F.

\begin{tabular}{cccccccccc}
\hline Spot & $\mathrm{C}(\mathrm{at} \%)$ & $\mathrm{O}(\mathrm{at} \%)$ & $\mathrm{N}(\mathrm{at} \%)$ & $\mathrm{Ca}(\mathrm{at} \%)$ & $\mathrm{P}($ at\%) & $\mathrm{O} / \mathrm{C}$ & $\mathrm{N} / \mathrm{C}$ & $\mathrm{Ca} / \mathrm{P}$ & $\mathrm{N} / \mathrm{Ca}$ \\
\hline 1 & 22.9 & 56.1 & 3.2 & 10.7 & 7.1 & 2.45 & 0.14 & 1.5 & 0.31 \\
2 & 38.3 & 41.0 & 2.1 & 11.4 & 7.3 & 1.07 & 0.05 & 1.6 & 0.18 \\
3 & 20.4 & 50.7 & 1.2 & 17.1 & 10.6 & 2.48 & 0.06 & 1.6 & 0.07 \\
4 & 25.6 & 52.0 & 2.7 & 11.4 & 8.3 & 2.03 & 0.11 & 1.4 & 0.24 \\
\hline
\end{tabular}



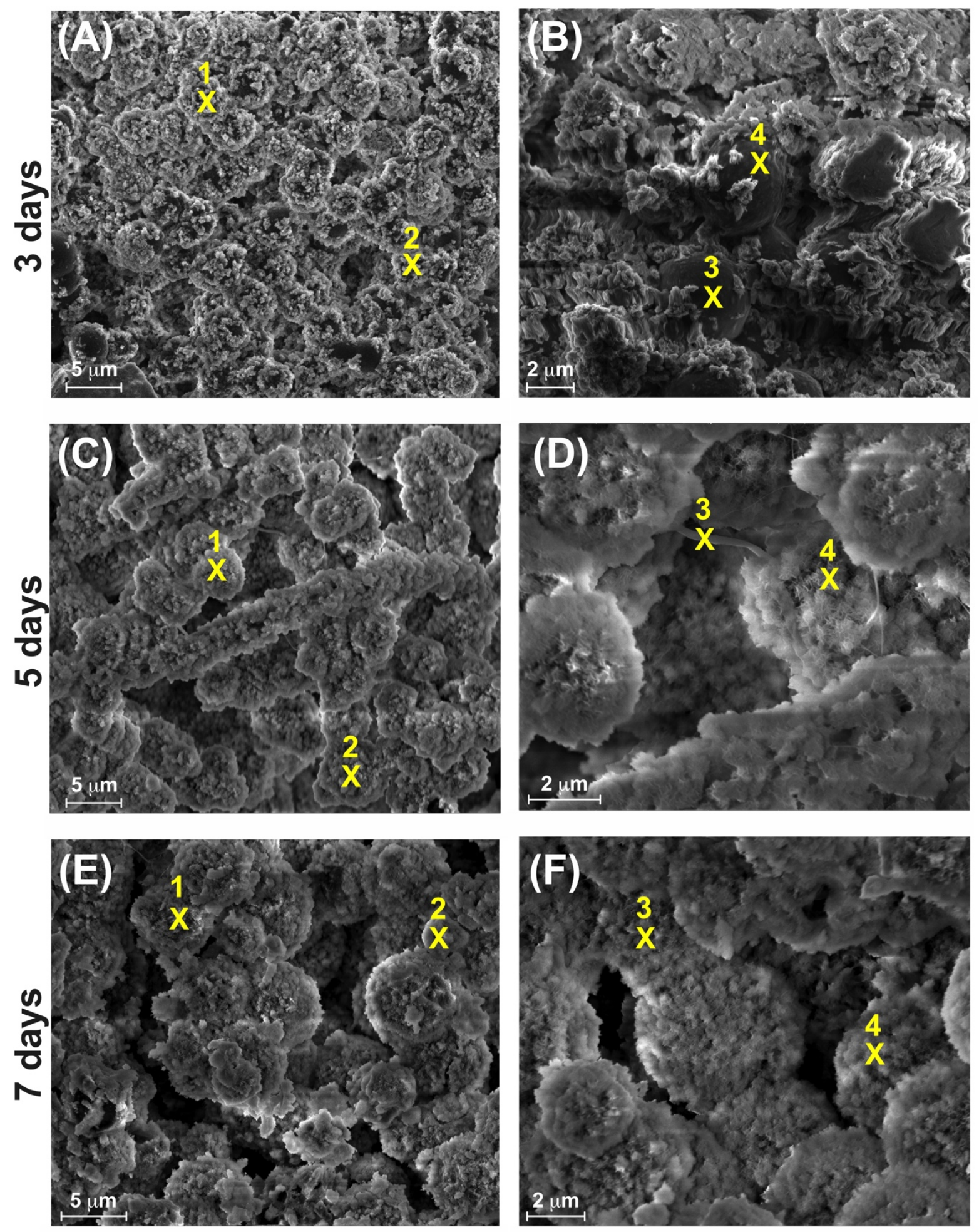

Figure S6. SEM images of ELP 3 membranes after incubation in $3 \times$ SBF for (A and $\mathbf{B}) 3$, (C and $\mathbf{D}) 5$, and (E and F) 7 days. The spots marked with "X" on all panels indicate the spots where EDS spectra were collected and they correspond to the data presented in Tables S9 (spots in A, B), S10 (spots in C, D), and S11 (spots in E, F). 
Table S9. Relative elemental atomic percentages measured by EDS in $\mathrm{ELP}_{3}$ membranes incubated in $3 \times$ SBF for 3 days. The spots 1-4 are shown in Figures S6A and S6B.

\begin{tabular}{cccccccccc}
\hline Spot & $\mathrm{C}(\mathrm{at} \%)$ & $\mathrm{O}($ at $\%)$ & $\mathrm{N}(\mathrm{at} \%)$ & $\mathrm{Ca}(\mathrm{at} \%)$ & $\mathrm{P}($ at $\%)$ & $\mathrm{O} / \mathrm{C}$ & $\mathrm{N} / \mathrm{C}$ & $\mathrm{Ca} / \mathrm{P}$ & $\mathrm{N} / \mathrm{Ca}$ \\
\hline 1 & 21.4 & 57.6 & 1.8 & 10.7 & 8.3 & 2.69 & 0.08 & 1.3 & 0.17 \\
2 & 35.7 & 45.0 & 1.2 & 8.2 & 5.9 & 1.26 & 0.03 & 1.4 & 0.15 \\
3 & 51.9 & 28.8 & 6.0 & 11.4 & 1.8 & 2.69 & 0.12 & 6.3 & 0.52 \\
4 & 48.8 & 33.4 & 2.2 & 15.7 & 0.1 & 0.68 & 0.05 & 157 & 0.14 \\
\hline
\end{tabular}

Table S10. Relative elemental atomic percentages measured by EDS in ELP 3 membranes incubated in $3 \times$ SBF for 5 days. The spots 1-4 are shown in Figures S6C and S6D.

\begin{tabular}{cccccccccc}
\hline Spot & $\mathrm{C}(\mathrm{at} \%)$ & $\mathrm{O}(\mathrm{at} \%)$ & $\mathrm{N}(\mathrm{at} \%)$ & $\mathrm{Ca}(\mathrm{at} \%)$ & $\mathrm{P}(\mathrm{at} \%)$ & $\mathrm{O} / \mathrm{C}$ & $\mathrm{N} / \mathrm{C}$ & $\mathrm{Ca} / \mathrm{P}$ & $\mathrm{N} / \mathrm{Ca}$ \\
\hline 1 & 13.4 & 59.5 & 2.9 & 13.3 & 10.0 & 4.44 & 0.22 & 1.3 & 0.22 \\
2 & 17.2 & 55.7 & 3.2 & 13.3 & 10.6 & 3.24 & 0.19 & 1.3 & 0.24 \\
3 & 11.5 & 38.4 & 2.2 & 30.6 & 17.3 & 3.34 & 0.19 & 1.8 & 0.07 \\
4 & 15.5 & 57.0 & 4.7 & 13.7 & 9.1 & 3.68 & 0.30 & 1.5 & 0.34 \\
\hline
\end{tabular}

Table S11. Relative elemental atomic percentages measured by EDS in $\mathrm{ELP}_{3}$ membranes incubated in $3 \times$ SBF for 7 days. The spots 1-4 are shown in Figures S6E and S6F.

\begin{tabular}{cccccccccc}
\hline Spot & $\mathrm{C}($ at\%) & $\mathrm{O}($ at\%) & $\mathrm{N}(\mathrm{at} \%)$ & $\mathrm{Ca}(\mathrm{at} \%)$ & $\mathrm{P}($ at\%) & $\mathrm{O} / \mathrm{C}$ & $\mathrm{N} / \mathrm{C}$ & $\mathrm{Ca} / \mathrm{P}$ & $\mathrm{N} / \mathrm{Ca}$ \\
\hline 1 & 18.4 & 43.0 & 3.1 & 21.3 & 14.2 & 2.34 & 0.17 & 1.5 & 0.15 \\
2 & 6.4 & 44.7 & 0.7 & 29.1 & 19.2 & 6.98 & 0.11 & 1.5 & 0.02 \\
3 & 15.9 & 55.2 & 1.4 & 16.6 & 11.0 & 3.47 & 0.09 & 1.5 & 0.08 \\
4 & 17.8 & 46.8 & 2.5 & 20.1 & 12.9 & 2.63 & 0.14 & 1.6 & 0.12
\end{tabular}


Table S12. Relative atomic percent of $\mathrm{C}, \mathrm{O}, \mathrm{N}, \mathrm{Ca}$, and $\mathrm{P}$, and $\mathrm{Ca} / \mathrm{P}$ and $\mathrm{N} / \mathrm{Ca}$ ratios on $\mathrm{ELP}_{3}$ membranes after incubation in $1.5 \mathrm{x}, 2 \mathrm{x}$, and $3 \times \mathrm{SBF}$, measured by XPS survey. No other elements were detected.

\begin{tabular}{|c|c|c|c|c|c|c|c|c|}
\hline $\begin{array}{c}\text { SBF } \\
\text { solution }\end{array}$ & $\begin{array}{l}\text { Time point } \\
\text { (days) }\end{array}$ & $\underset{(\text { at\%) }}{\mathrm{C}}$ & $\mathrm{O}(\mathrm{at} \%)$ & $N(a t \%)$ & $\mathrm{Ca}(\mathrm{at} \%)$ & $\mathrm{P}(\mathrm{at} \%)$ & $\mathrm{Ca} / \mathrm{P}$ & $\mathrm{N} / \mathrm{Ca}$ \\
\hline \multirow[t]{2}{*}{ I } & 0 & $68 \pm 3$ & $19 \pm 3$ & $13 \pm 1$ & $\mathrm{~N}$ & $\mathrm{~N}$ & l & I \\
\hline & 3 & $67 \pm 2$ & $22 \pm 3$ & $11 \pm 1$ & $0.3 \pm 0.1^{* * *+++}$ & $0.2 \pm 0.1$ & $1.5 \pm 0.2$ & $37 \pm 8$ \\
\hline \multirow[t]{4}{*}{$1.5 \times \mathrm{SBF}$} & 5 & $67 \pm 1$ & $21 \pm 2$ & $11 \pm 1$ & $0.7 \pm 0.1^{* * *+++}$ & $0.5 \pm 0.1$ & $1.5 \pm 0.1$ & $17 \pm 3$ \\
\hline & 7 & $66 \pm 4$ & $21 \pm 2$ & $11 \pm 2$ & $1.6 \pm 0.2^{* \star *+++}$ & $0.9 \pm 0.2$ & $1.7 \pm 0.1$ & $7 \pm 2$ \\
\hline & 21 & $59 \pm 3$ & $23 \pm 3$ & $10 \pm 1$ & $4.8 \pm 0.8$ & $3.0 \pm 0.9$ & $1.8 \pm 0.3$ & $2.2 \pm 0.6$ \\
\hline & 3 & $65 \pm 2$ & $20 \pm 3$ & $9 \pm 2$ & $3 \pm 0.7^{* * *}$ & $2.1 \pm 0.4$ & $1.4 \pm 0.1$ & $3.0 \pm 1.0$ \\
\hline \multirow[t]{3}{*}{$2 \times \mathrm{SBF}$} & 5 & $52 \pm 4$ & $30 \pm 2$ & $8 \pm 2$ & $5.8 \pm 0.8^{* * \star \dagger}$ & $3.9 \pm 0.7$ & $1.5 \pm 0.1$ & $1.4 \pm 0.6$ \\
\hline & 7 & $30 \pm 3$ & $49 \pm 2$ & $5 \pm 1$ & $9.8 \pm 0.6^{* * * \dagger}$ & $6.4 \pm 0.5$ & $1.5 \pm 0.1$ & $0.6 \pm 0.2$ \\
\hline & 3 & $55 \pm 5$ & $30 \pm 4$ & $8 \pm 2$ & $4.2 \pm 0.9^{+++}$ & $2.8 \pm 0.8$ & $1.5 \pm 0.1$ & $1.9 \pm 0.7$ \\
\hline \multirow[t]{2}{*}{$3 \times \mathrm{SBF}$} & 5 & $24 \pm 3$ & $47 \pm 2$ & $1.7 \pm 0.5$ & $15.4 \pm 0.8^{+++} \dagger$ & $10.6 \pm 0.7$ & $1.5 \pm 0.2$ & $0.1 \pm 0$ \\
\hline & 7 & $22 \pm 3$ & $46 \pm 3$ & $1.5 \pm 0.5$ & $18 \pm 1^{+++}+$ & $11.8 \pm 0.6$ & $1.5 \pm 0.2$ & $0.1 \pm 0$ \\
\hline
\end{tabular}


Table S13. FTIR peak assignments for calcified $\mathrm{ELP}_{3}$ membranes and HA.

\begin{tabular}{|c|c|c|c|}
\hline Peak $\left(\mathrm{cm}^{-1}\right)$ & Calcified $\mathrm{ELP}_{3}$ membrane & $\mathrm{HA}$ & References \\
\hline$\vee \mathrm{OH}$ & $3290-3300$ & 3300 & \\
\hline v N-H & $2958-2964$ & & \\
\hline $\mathrm{Vas}_{\mathrm{as}} \mathrm{CH}_{2}$ & 2926-2929 & & \\
\hline $\mathrm{v}_{\mathrm{s}} \mathrm{CH}_{2}$ & $2865-2868$ & & \\
\hline$\vee \mathrm{C}=\mathrm{O}$ (amide I) & $1638-1642$ & & (17), (18), (19) \\
\hline v C-N, $\delta \mathrm{N}-\mathrm{H}$ (amide II) & $1535-1540$ & & (17), (18), (19) \\
\hline$\delta \mathrm{CH}_{2}$ & $1443-1451$ & & (20) \\
\hline$\delta \mathrm{CH}_{3}$ & $1365-1372$ & & (17), (19), (20) \\
\hline$\delta \mathrm{C}-\mathrm{H}$ (amide III) & $1232-1236$ & & (17) \\
\hline $\mathrm{V}_{3} \mathrm{PO}_{4}{ }^{3-}$ & $1109-1110$ & 1091 & $\begin{array}{c}(18),(21),(22) \\
(23)\end{array}$ \\
\hline $\mathrm{V}_{3} \mathrm{PO}_{4}{ }^{3-}$ & $1027-1031$ & 1031 & $\begin{array}{c}(18),(21),(22) \\
(23)\end{array}$ \\
\hline $\mathrm{V}_{1} \mathrm{PO}_{4}^{3-}$ & $960-963$ & 962 & $\begin{array}{c}\text { (18), (21), (22), } \\
(23)\end{array}$ \\
\hline $\mathrm{v}_{2} \mathrm{CO}_{3}^{2-}$ & $864-867$ & & $\begin{array}{c}\text { (18), (21), (22), } \\
(24)\end{array}$ \\
\hline $\mathrm{V}_{4} \mathrm{PO}_{4}{ }^{3-}$ & $600-602$ & 602 & \\
\hline $\mathrm{V}_{4} \mathrm{PO}_{4}^{3-}$ & $561-563$ & 564 & \\
\hline
\end{tabular}

$\mathrm{v}_{\mathrm{as}}$ : antisymmetric stretching; $v_{\mathrm{s}}$ : symmetric stretching; $\delta$ : bending 


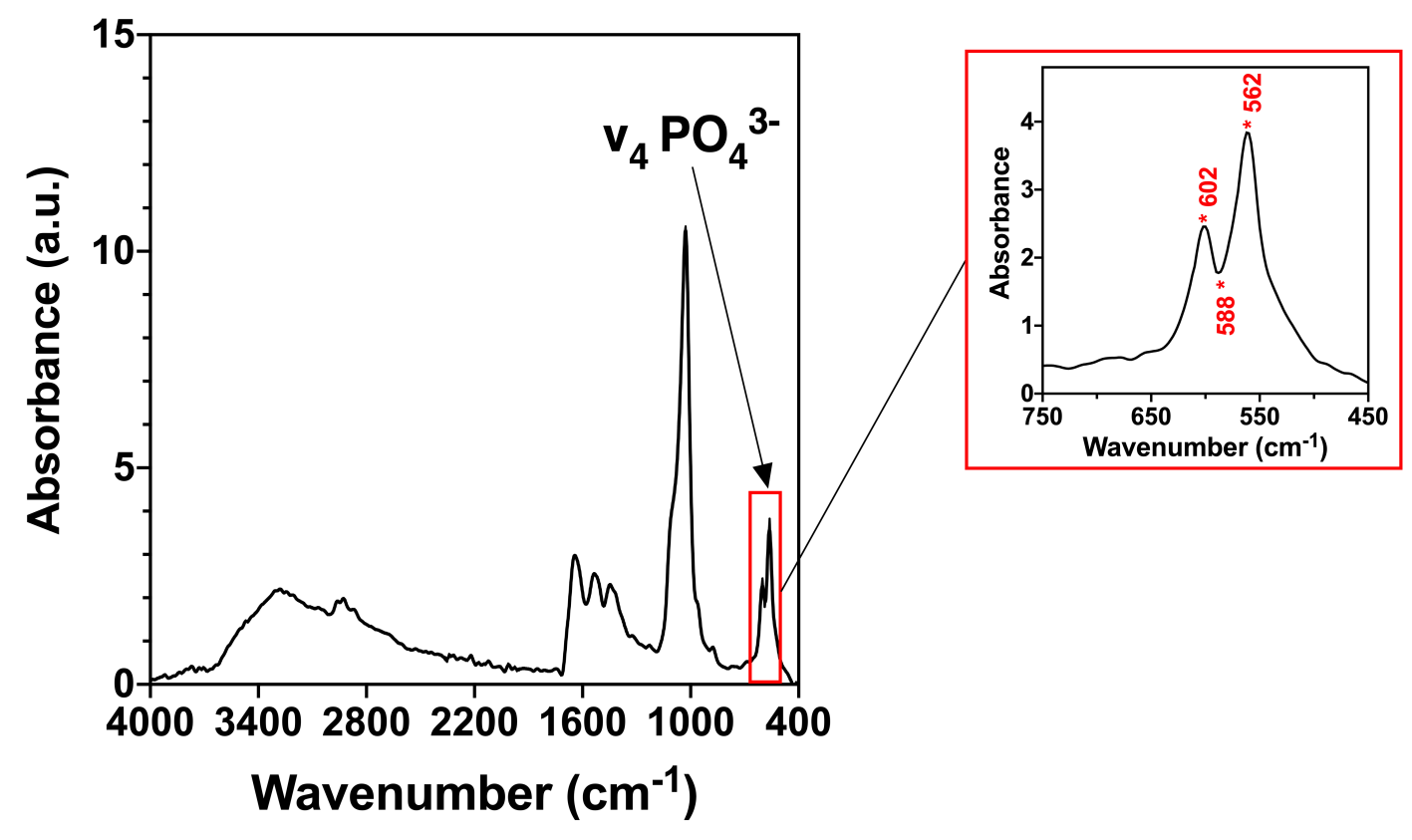

Figure S7. Representative FTIR spectrum of calcified ELP3 membraned incubated in $1.5 \mathrm{x}$ SBF for 21 days showing the degenerated $v_{4}$ phosphate band used in Shemesh's method to determine the mineral crystallinity (4).

Table S14. Experimental mineral crystallinity indexes $(\mathrm{Cl})$ measured in calcified ELP 3 membranes and HA based on the FTIR $v_{4}$ vibration peaks.

\begin{tabular}{|c|c|c|}
\hline SBF solution & Time point (days) & $\mathrm{Cl}$ \\
\hline \multirow[b]{2}{*}{$1.5 \times \mathrm{SBF}$} & 7 & $3.3 \pm 0.1^{*+\# \#}$ \\
\hline & 21 & $4.2 \pm 0.2^{\# \#}$ \\
\hline $2 \times \mathrm{SBF}$ & 7 & $2.6 \pm 0.2^{*}$ \\
\hline $3 \times \mathrm{SBF}$ & 7 & $2.6 \pm 0.1^{+}$ \\
\hline $\mathrm{HA}$ & l & $5.6 \pm 0.3$ \\
\hline
\end{tabular}


Table S15. Experimental XRD FWHM values of the peak corresponding to the planes (211), (121), and (202) in ELP 3 membranes incubated in $1.5 \times$ SBF for 7 and 21 days, and in $2 \times$ SBF and $3 \times$ SBF for 7 days.

\begin{tabular}{|c|c|c|}
\hline SBF solution & Time point (days) & XRD FWHM \\
\hline \multirow[b]{2}{*}{$1.5 \times \mathrm{SBF}$} & 7 & $1.2 \pm 0.1^{*+\#}$ \\
\hline & 21 & $0.7 \pm 0.2^{\#}$ \\
\hline $2 \times \mathrm{SBF}$ & 7 & $1.8 \pm 0.2^{*}$ \\
\hline $3 \times$ SBF & 7 & $1.9 \pm 0.2^{+}$ \\
\hline
\end{tabular}

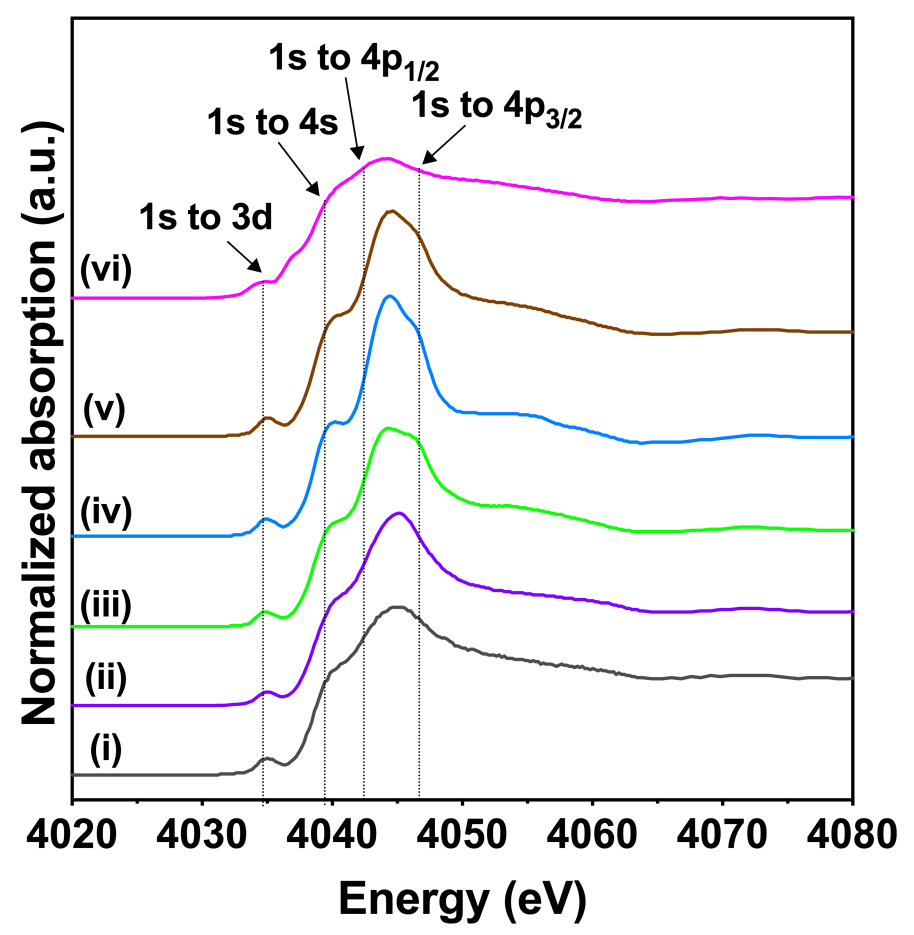

Figure S8. Representative Ca K-edge NEXAFS reference spectra of (i) $\mathrm{ELP}_{3}-\mathrm{Ca}^{2+}$, (ii) ACP, (iii) DCPD, (iv) OCP, (v) HA, (vi) CHA, and (vii) $\beta$-TCMP. 
Table S16. Percentages of $\mathrm{ELP}_{3}-\mathrm{Ca}^{2+}, \mathrm{ACP}, \mathrm{OCP}, \mathrm{HA}$, and $\mathrm{CHA}$ in $\mathrm{ELP}_{3}$ membranes incubated in $1.5 \times, 2 \times$, and $3 \times$ SBF solutions determined by LCF using Ca K-edge NEXAFS spectra of reference samples, and R-factors of the LCF.

\begin{tabular}{|c|c|c|c|c|c|c|c|}
\hline $\begin{array}{c}\text { SBF } \\
\text { solution }\end{array}$ & $\begin{array}{l}\text { Time point } \\
\text { (days) }\end{array}$ & $\begin{array}{c}\mathrm{ELP}_{3}-\mathrm{Ca}^{2+} \\
(\%)\end{array}$ & ACP (\%) & OCP (\%) & $\mathrm{HA}(\%)$ & $\begin{array}{l}\mathrm{CHA} \\
(\%)\end{array}$ & R-factor \\
\hline \multirow{4}{*}{$1.5 \times$ SBF } & 3 & $30 \pm 5$ & $27 \pm 7^{*++}$ & $21 \pm 5^{++}$ & $15 \pm 5^{* *++}$ & $7 \pm 2$ & $0.007 \pm 0.003$ \\
\hline & 5 & $24 \pm 4^{+++}$ & $19 \pm 3^{* *++}$ & $20 \pm 6^{++}$ & $19 \pm 3^{\star *+++}$ & $10 \pm 4$ & $0.003 \pm 0.001$ \\
\hline & 7 & $20 \pm 4^{\star \star \star *++}$ & $16 \pm 3^{\star \star \star+++}$ & $17 \pm 3^{*+++}$ & $33 \pm 3^{* *+++}$ & $14 \pm 5^{*}$ & $0.005 \pm 0.002$ \\
\hline & 21 & 0 & $10 \pm 3$ & $10 \pm 2$ & $51 \pm 6$ & $29 \pm 2$ & $0.0003 \pm 0.0001$ \\
\hline \multirow{3}{*}{$2 \times \mathrm{SBF}$} & 3 & $26 \pm 4$ & $11 \pm 2^{*}$ & $14 \pm 3$ & $39 \pm 6^{* *}$ & $10 \pm 4$ & $0.005 \pm 0.0002$ \\
\hline & 5 & $20 \pm 4^{\dagger \dagger \dagger}$ & $9 \pm 3^{* *}$ & $14 \pm 4$ & $42 \pm 5^{* * \dagger \dagger}$ & $15 \pm 3$ & $0.0002 \pm 0.0001$ \\
\hline & 7 & $0^{* * *}$ & $0^{* * *}$ & $7 \pm 3^{* \dagger}$ & $68 \pm 5^{* *} \dagger$ & $25 \pm 5^{*}$ & $0.003 \pm 0.001$ \\
\hline \multirow{3}{*}{$3 \times \mathrm{SBF}$} & 3 & $25 \pm 4$ & $9 \pm 3^{++}$ & $10 \pm 5^{++}$ & $46 \pm 3^{++}$ & $10 \pm 4$ & $0.002 \pm 0.0005$ \\
\hline & 5 & $0^{++++\dagger \dagger}$ & $4 \pm 1^{++}$ & $7 \pm 3^{++}$ & $75 \pm 4^{+++}+\dagger$ & $14 \pm 3$ & $0.0004 \pm 0.0001$ \\
\hline & 7 & $0^{+++}$ & $0^{+++}$ & $0^{+}$ & $84 \pm 6^{\dagger}$ & $16 \pm 5$ & $0.0004 \pm 0.0001$ \\
\hline
\end{tabular}




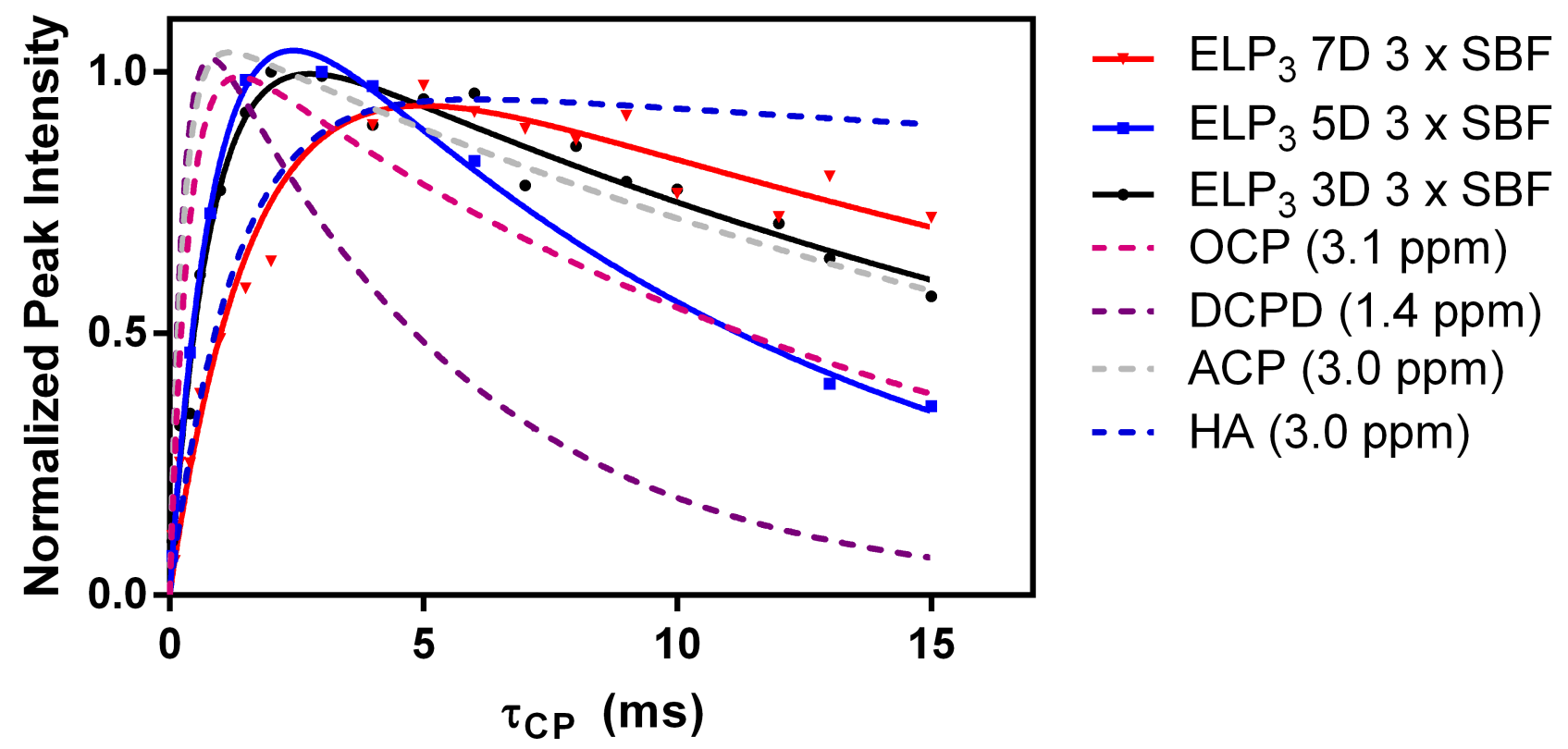

Figure S9. Integrated ${ }^{31} \mathrm{P}$ peak intensities are plotted as a function of ${ }^{1} \mathrm{H}-{ }^{31} \mathrm{P}$ CP contact time $\left(\tau_{\mathrm{CP}}\right)$, for $\mathrm{ELP}_{3}$ membranes incubated in $3 \times \mathrm{SBF}$ and for Ca-P standard compounds. Lines represent the best fits obtained for each data set using Eq. 1, and were used to calculate the parameters $\mathrm{T}_{\mathrm{CP}}$ and $\mathrm{T}^{1} \rho$, shown in Table 1. 

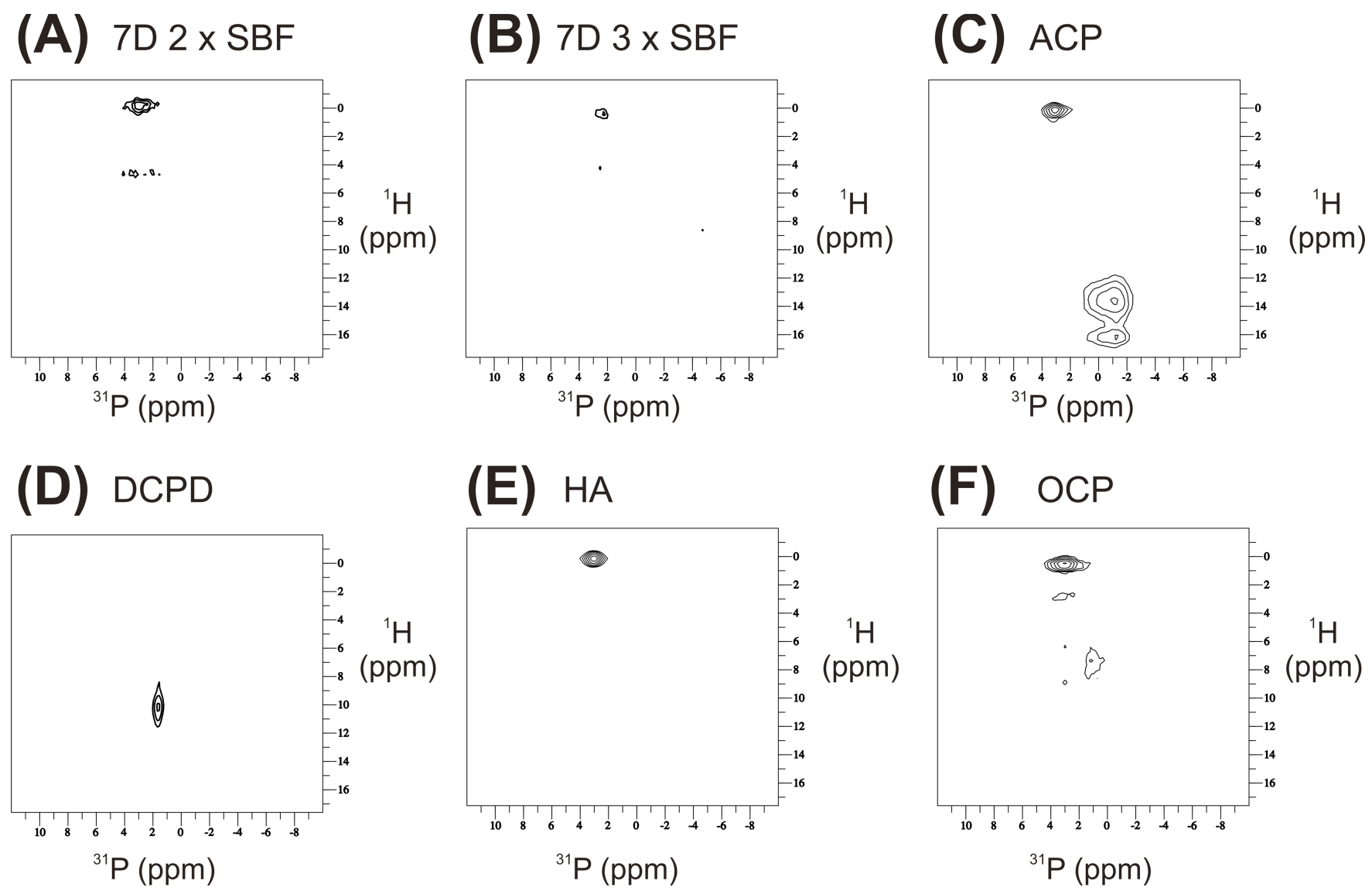

Figure S10. ${ }^{1} \mathrm{H}-{ }^{31} \mathrm{P}$ HETCOR spectra recorded at $10 \mathrm{kHz}$ MAS for ELP 3 membranes and Ca-P reference compounds. 2D spectra are shown for samples incubated in (A) $2 \times$ SBF for 7 days,

(B) $3 \times$ SBF for 7 days, as well as for ACP (C), DCPD (D), HA (E), and OCP (F). Each spectrum is plotted at approximately the same level above the noise, such that variations in peak intensity are representative of the signal to noise ratios in each sample. 


\section{Section 3: Supplemental references}

1. Ohtsuki, C.; Kokubo, T.; Yamamuro, T., Mechanism of apatite formation on CaO-SiO2-P2O5 glasses in a simulated body fluid. J. Noncryst. Solids. 1992, 143, 84-92.

2. Davies, J., Ion association. London: Butterworth Press. 1962.

3. McDowell, H.; Gregory, T. M.; Brown, W. E., Solubility of Ca5(PO4)3OH in the System $\mathrm{Ca}(\mathrm{OH}) 2-\mathrm{H} 3 \mathrm{PO} 4-\mathrm{H} 2 \mathrm{O}$ at 5, 15, 25, and $37^{\circ} \mathrm{C}$. J. Res. Natl. Bur. Stand. 1977, 81A, 273- 281.

4. Shemesh, A., Crystallinity and diagenesis of sedimentary apatites. Geochim. Cosmochim. Acta. 1990, 54 (9), 2433-2438.

5. Termine, J.; Posner, A., Infrared analysis of rat bone: Age dependency of amorphous and crystalline mineral fraction. Science. 1966, 113 (3743), 1523-1525.

6. Koningsberger, D.; Mojet, B.; Van Dorssen, G.; Ramaker, D., XAFS spectroscopy; fundamental principles and data analysis. Top. Catal. 2000, 10 (3-4), 143-155.

7. Gourgas, O.; Marulanda, J.; Zhang, P.; Murshed, M.; Cerruti, M., Multidisciplinary Approach to Understand Medial Arterial Calcification. Arterioscler. Thromb. Vasc. Biol. 2018, 38 (2), 363372.

8. LeGeros, R., Formation and transformation of calcium phosphates: relevance to vascular calcification. Z. Kardiol. 2001, 90 (3), 116-124.

9. Schlieper, G.; Aretz, A.; Verberckmoes, S.; Krüger, T.; Behets, G.; Ghadimi, R.; Weirich, T.; Rohrmann, D.; Langer, S.; Tordoir, J.; Amann, K.; Westenfeld, R.; Brandenburg, V.; D'Haese, P.; Mayer, J.; Ketteler, M.; McKee, M.; Floege, J., Ultrastructural analysis of vascular calcifications in uremia. J. Am. Soc. Nephrol. 2010, 21 (4), 689-696.

10. Verberckmoes, S.; Persy, V.; Behets, G.; Neven, E.; Hufkens, A.; Zebger-Gong, H.; Müller, D.; Haffner, D.; Querfeld, U.; Bohic, S.; De Broe, M.; D'Haese, P., Uremia-related vascular calcification: more than apatite deposition. Kidney Int. 2007, 71 (4), 298-303.

11. Cottignoli, V.; Cavarretta, E.; Salvador, L.; Valfré, C.; Maras, A., Morphological and chemical study of pathological deposits in human aortic and mitral valve stenosis: a biomineralogical contribution. Patholog. Res. Int. 2014, 2015, 1-14.

12. Prieto, R.; Gomila, I.; Söhnel, O.; Costa-Bauza, A.; Bonnin, O.; Grases, F., Study on the structure and composition of aortic valve calcific deposits: etiological aspects. J. Biophys. Chem. 2011, 2 (1), 19-25.

13. Gourgas, O.; Muiznieks, L.; Guadarrama Bello, D.; Nanci, A.; Sharpe, S., Crosslinked Elastin-Like Polypeptide Membranes as a Model for Medial Arterial Calcification. Biomacromolecules 2019, 20 (7), 2625-2636.

14. Gaur, A.; Shrivastava, B.; Joshi, S., Copper K-edge XANES of $\mathrm{Cu}$ (I) and $\mathrm{Cu}$ (II) oxide mixtures. J. Phys.: Conf. Ser. 2009, 190, 012084.

15. Ravel, B.; Newville, M., ATHENA, ARTEMIS, HEPHAESTUS: data analysis for X-ray absorption spectroscopy using IFEFFIT. J. Synchrotron Radiat. 2005, 12 (pt4), 537-541.

16. Cosmidis, J.; Benzerara, K.; Nassif, N.; Tyliszczak, T.; Bourdelle, F., Characterization of Ca-phosphate biological materials by scanning transmission X-ray microscopy (STXM) at the Ca L2,3-, P L2,3- and C K-edges. Acta Biomater. 2015, 12, 260-269.

17. Popescu, M.; Vasile, C.; Craciunescu, O., Structural analysis of some soluble elastins by means of FT-IR and 2D IR correlation spectroscopy. Biopolymers. 2010, 93 (12), 1072-1084.

18. Vyavahare, N.; Ogle, M.; Schoen, F.; Levy, R., Elastin Calcification and its Prevention with Aluminum Chloride Pretreatment. Am. J. Pathol. 1999, 155 (3), 973-982.

19. Serrano, V.; Liu, W.; Franzen, S., An Infrared Spectroscopic Study of the Conformational Transition of Elastin-Like Polypeptides. Biophys. J. 2007, 93 (7), 2429-2435. . 
20. Belbachir, K.; Noreen, R.; Gouspillou, G.; Petibois, C., Collagen types analysis and differentiation by FTIR spectroscopy. Anal. Bioanal. Chem. 2009, 395 (3), 829-837.

21. Salenius, J.; Brennan, J.; Miller, A.; Wang, Y.; Aretz, T.; Sacks, B.; Dasari, R.; Feld, M., Biochemical composition of human peripheral arteries examined with Near-Infrared Raman Spectroscopy. J. Vasc. Surg. 1998, 27 (4), 710-719.

22. Koutsopoulos, S., Synthesis and Characterization of hydroxyapatite crystals: a review study on the analytical methods. J. Biomed. Mater. Res., Part A 2002, 62 (4), 600-612.

23. Rey, C.; Shimizu, M.; Collins, B.; Glimcher, M. J., Resolution-enhanced Fourier transform infrared spectroscopy study of the environment of phosphate ions in the early deposits of a solid phase of calcium-phosphate in bone and enamel, and their evolution with age. I: Investigations in the v4 PO4 domain. Calcif. Tissue Int. 1990, 46, 384-394.

24. Rey, C.; Renugopalakrishnan, V.; Shimizu, M.; Collins, B.; Glimcher, M. J., A resolutionenhanced Fourier Transform Infrared spectroscopic study of the environment of the CO32- ion in the mineral phase of enamel during its formation and maturation. Calcif. Tissue Int. 1991, 49 (4), 259-268. 